\section{Step-By-Step Rehabilitation Of Children With Congenital Clearance Of The Upper Lip And Palate}

\author{
Mirxayidov Miraziz Mirxoliq O'g'li \\ Doctoral Student In Department Of Children Maxillafacial \\ Surgeon, Tashkent State Dental Institute, Uzbekistan
}

\author{
G OPEN ACCESS \\ The American Journal of \\ Medical Sciences And \\ Pharmaceutical \\ Research \\ JULY 2020 \\ Page No.: 94-104 \\ Volume-II Issue-VII \\ PUBLISHED: 30 JULY 2020 \\ www.usajournalshub.com/inde \\ x.php/TAJMSPR \\ Copyright: Original content \\ from this work may be used \\ under the terms of the \\ Creative Commons Attribution \\ 4.0 licence.
}

\title{
Abstract
}

This article gives information on Step-by-step rehabilitation of children with congenital clearance of the upper lip and palate. A review of the reported data on the frequency of birth, prevalence, territorial peculiarities, clinical manifestations, organization of medical aid to children with congenital cleft lip and palate, staged rehabilitation is presented in the paper.

Key words: congenital cleft lip and palate, congenital dentofacial anomalies, congenital malformation, staged rehabilitation.

Introduction: A review of the reported data on the frequency of birth, prevalence, territorial peculiarities, clinical manifestations, organization of medical aid to children with congenital cleft lip and palate, staged rehabilitation is presented in the paper.

One of the most common types of congenital malformations (congenital malformations) are malformations of the maxillofacial region, which occur with a frequency of 1: 700-1: 1000 , of which congenital clefts of the upper lip and / or palate (CRGN) accounts for $90 \%$ $[1-3,5]$. 
Congenital clefts of the upper lip and / or palate are a severe congenital condition characterized by the presence of not only a local anatomical defect, but also concomitant systemic disorders of respiration, nutrition and speech $[1-3,5,7,8,23,24]$.

There are various approaches to the therapy of ERGN $[1-3,5,27-30]$.

In the overwhelming majority of cases at the present stage, with timely medical and speech therapy assistance, it is possible to create all the necessary conditions for the full physical and mental development of the child $[1-3,7,8,15,17,18,20]$.

The aim of the work is to analyze the literature data on the frequency of birth, prevalence, territorial characteristics, clinical manifestations, organization of medical care for children with congenital cleft lip and palate and their gradual rehabilitation.

Research results. According to domestic and foreign literature, the dentist should be fully responsible for the early diagnosis of CULP and stage-by-stage rehabilitation together with other specialists.

Every year in the Republic of Uzbekistan 3,000 children are born with congenital anomalies of the face, neck and skull, of which $70 \%$ - with anomalies of the maxillofacial system [1-3, 8-11, 15-20]. The overall incidence of morphological malformations in children under 1 year of age is approximately 27.2 per 1000 population. About $60 \%$ of them are detected in the first 7 days of life already in obstetric institutions $[1-6,8,9,15]$. CULP are found in the form of various options: isolated clefts of the upper lip (hidden, incomplete, complete), isolated clefts of the palate (hidden, uvula of the soft palate, soft palate, soft and posterior part of the hard palate, complete cleft palate), through clefts, unilateral, bilateral) $[8-16,18,19,21,22]$.

The modern tactics for the birth of children with ERH in the leading dental clinics of the Russian Federation and abroad is as follows: for the birth of a child with a defect in the maxillofacial region within the first 3 days. it is necessary to send an emergency notification (special form) to the Center for Maxillofacial Surgery (Maxillofacial Surgery). After receiving an emergency notification, the head of the Center organizes an urgent visit of a dental surgeon to conduct a detailed examination, determine the scope of necessary measures to implement adequate feeding of the child and the orthodontist to resolve the issue of making an obturator as a removable prosthesis $[2,3,7,21,22]$. 
The following persons have the right to call specialists for emergency consultation:

- chief obstetricians, neonatologists, pediatricians, dental surgeons and other chief specialists of districts and cities;

- heads of maternity, neonatological, surgical pediatric departments of medical institutions in districts and cities;

- at night and on weekends, the doctors on duty of the indicated treatment units under the supervision of the heads of the respective departments.

By the time the dental surgeon arrives, the newborn should be examined by a neonatologist (district or city pediatrician if necessary) for other birth defects. If they are found, the pediatrician will arrange a consultation with any specialist.

During the initial examination, the dental surgeon establishes an accurate diagnosis, determines the state of the child's physical development and the risk group for the development of concomitant diseases, gives recommendations on the nature and method of feeding. At the same time, the doctor recommends the persistent attachment of the baby to the breast, the development of the mother's patience when feeding him, teaches the expression of milk residues in order to maintain lactation longer [1, 23-25].

In cases where breastfeeding is impossible, the nursing staff and the mother of the child are trained to feed from a nipple or spoon (the nipple should be long to close the defect and create better conditions for the sucking act, it should have several holes, the most adapted are NUK nipples).

A release plate should be made if necessary.

Together with a neonatologist, a dental surgeon develops recommendations on the feeding regimen for a child with ADH (feeding is allowed after 2-2.5 hours 8-10 times / day), conducts psycho-preventive work with the child's mother, explains the features of congenital defect, as well as feeding and care for a child with WRHN, informs about the possibilities of surgical and restorative treatment, the need for dispensary observation and treatment in a specialized Center, genetic counseling.

The dental surgeon gives the mother and the medical staff a memo indicating the address and telephone number of the Center, consultation days and hours of admission, and the time of the initial consultation of a particular child. On the eve of discharge from the 
hospital, the head nurse transfers information about the newborn to the district children's clinic, where, on the basis of this information, the patronage of the newborn is recorded in the call logdoctor at home. The local pediatrician and nurse visit the newborn on the first day after discharge from the hospital. In the first 3-5 days after the discharge of a child with CULP, the head of the outpatient pediatric department should examine. The district pediatrician carries out further observation according to an individual plan, keeps a diary of observations. A pediatric doctor at the site visits a child with CULP every week of the first month of life, a nurse - every day.

Early surgical treatment protocols are generally accepted in Western Europe, the United States and Canada. They, according to leading experts, ensure the achievement of optimal cosmetic and functional results: natural and symmetrical facial contours, normal speech and physiological occlusion $[1-3,7,8,15,17,18,20-22,29,30]$.

The goal of treating a child with a congenital cleft of the upper lip and palate is not only to eliminate the defect, but also to achieve ideal facial contours, normal speech, and to demonstrate a beautiful and continuous dentition $[2,3,7,20,23-26,28]$.

The optimal protocol for surgical treatment of patients, developed at the CULP of Ministry of Health of the Republic Uzbekistan [1-3, 23-25] for children, includes the following main stages:

1. Primary cheilorinoplasty (plastic surgery of the upper lip and nose) for any types of clefts of the upper lip at the age of 1 month.

2. Plastic surgery of the soft palate at the age of 6-8 months.

3. Plasty of the hard palate at the age of 12-14 months.

4. Bone grafting of the alveolar ridge of the upper jaw at the age of 8-12 years.

5. Reconstructive surgery (if necessary) at any age.

After receiving an emergency notification, the head of the department organizes an urgent visit of a dental surgeon to conduct an examination, to determine the amount of necessary measures to implement adequate feeding of the child and an orthodontist to resolve the issue of making an obturator as a removable prosthesis. In the Center for Maxillofacial Surgery, a child with CLAP should be examined at the age of one month. A pediatrician (pediatric dentist, surgeon, etc.) shall refer the patient for a consultation at 
the Center.

When arriving for a consultation, patients must have: 1) a referral from a doctor; 2) a detailed certificate from the maternity hospital - the passport of the newborn, which should reflect the data of the initial examination, anthropometric indicators, the results of some auxiliary diagnostic studies (if any); 3) a detailed conclusion of the pediatrician on the dynamics of anthropometric indicators, neuropsychic development of the child for the first month of life, data of clinical and laboratory examination; 4) a certificate of antenatal care with an indication of the characteristics of the course of pregnancy, examinations that were carried out during pregnancy, and their results; 5) a certificate of the health status of the parents.

During the initial examination of the child at the Center, a dispensary observation card is entered on him and an individual program for further treatment and rehabilitation is developed. The program is made by a group of specialists taking into account the nature of the defect and the general condition of the child. It specifies the sequence of treatment carried out by specialists with an indication of the feasible time frame for each stage. At the age of 3-6 months, and then at 6-12 months, an ongoing consultation is carried out at the Center, after which, according to indications (depending on the type of cleft), hospitalization is carried out for surgical treatment.

When performing primary plastic surgery of the upper lip and nose, it is necessary to restore the normal anatomy of the nasolabial region as efficiently as possible. This is what makes it possible to achieve symmetrical and even contours of the upper lip and nose, natural lines of the face in combination with its normal facial expressions, deep arch of the vestibule of the oral cavity and restoration of the correct position of the fragments of the upper jaw [23-25].

When performing plastic surgery of the palate, it is necessary to timely recreate the mobile soft palate, ensure the normal size of the pharyngeal ring, effectively and nontraumatically eliminate the defect of the hard palate. This is the key to the formation of normal speech in the baby and the prevention of the occurrence of deformities of the upper jaw, and hence of the face and bite $[2,16,17,23-25]$.

During the formation of a permanent bite, it is necessary to restore the continuity of the 
alveolar process of the upper jaw by performing bone grafting and to achieve an attractive and even dentition using modern orthodontic appliances.

Preliminarily, in order to prepare for staged cheiloplasty of a child with CLAP, the district pediatrician supervises, who prescribes an in-depth clinical and laboratory examination. In the postoperative period, measures are taken to prevent complications and secondary deformities: orthodontic treatment, endonasal activators, exercise therapy, general and local massages, and other methods of physiotherapeutic effects.

At the age of 1-2 years, a child with CLAP is monitored at the Center once every 6 months, after which, according to indications, hospitalization is made for surgical treatment. During this period of time, the pediatrician continues to supervise the patient, controls his physical and psycho-emotional development. The speech therapist carries out speech therapy training.

At the age of 2-4 years and 5-7 years, dispensary registration is carried out with the same frequency and volume.

At the same time, the child is being adapted to enter kindergarten and then to school. Cyclic stationary speech therapy training of the patient is carried out, according to indications - hospitalization for surgical treatment. At the age of 7-15, the current consultation in the Center is carried out once every 1-2 years. At this stage of clinical examination, according to indications, surgical elimination of secondary deformities and surgical correction of the occlusion are performed along with general health, preventive measures, orthodontic treatment. Provide the most complete social and pedagogical rehabilitation, after which they are removed from the dispensary register.

The timing and methods of treatment of patients with CLAP depend on the child's health, his physical and psychomotor development, the presence of concomitant diseases or other congenital malformations, as well as organizational reasons. Only a timely started treatment, carried out with the effective help of parents, with the participation of the proper spectrum of related specialists, makes possible the practical recovery of $80 \%$ of children.

Control over the success of the consolidation of knowledge by parents and the effectiveness of various types of activities (speech therapy, physical, etc.) and medical 
and recreational activities are primarily carried out by a district pediatrician and a specialist of the Center. Prevention of postoperative complications of both local and general somatic nature is of great importance in the complex treatment of children with CLAP $[1,2$, 23-25].

Underestimation of the initial status of the child, omissions in the diagnosis of congenital, concomitant or sluggish diseases in the postoperative period, as a rule, sharply worsen the early course of the disease, which is manifested by partial or complete divergence of the edges of the surgical wound, exacerbation of chronic diseases, primarily from the ENT organs, respiratory, cardiovascular and immune systems.

The success of surgical treatment in the majority of children with CRHN depends on the timely implementation of comprehensive training in the conditions of dispensary observation $[1,2,23-25]$.

When deciding on an operation, this contingent has a high responsibility of the pediatrician, who gives permission for surgical treatment. The pediatrician reinforces his conclusion about the possibility of this in a child with other congenital malformations or diseases with the positive conclusions of narrow specialists (cardiologist, nephrologist, pulmonologist, endocrinologist, etc.). The dental surgeon, leading and coordinating the work of consultant doctors, determines the timing and scope of surgical treatment, controls the timeliness of referral of children for consultation to narrow specialists and the conduct of preventive treatment, together with them, determines the absolute and relative contraindications for surgery.

An absolute contraindication is circulatory insufficiency of IA and IIB degrees.

Relative contraindications are: pronounced dystrophic changes in the myocardium, acute somatic and infectious diseases and not earlier than 2 months after recovery, hypotrophy of the I-III degree, rickets of the I III degree during the height of the peak, atopic dermatitis in the acute stage, anemia with erythrocyte count less than $3,5 \times 10^{12} /$, hemoglobin less than $120 \mathrm{~g} / \mathrm{l}$, color index less than 0.75 , chronic diseases within 6 months after exacerbation, chronic nephritis with symptoms of renal failure, dermatitis and eczema in the face, mucosal lesions. Children with relative contraindications are given specific treatment for concomitant pathology (on an outpatient basis or in specialized 
hospitals) and, with positive dynamics, surgical treatment is allowed.

Tasks for specialist doctors and main periods of active observation:

Pediatrician: organization of differentiated medical supervision, control of indicators of the child's physical development, control over the child's living conditions, nutrition and care (social conditions, feeding, adherence to the daily routine and hygiene regime, literacy of staff and parents, their desire to raise the child), planning the main pathways health improvement of the child, prevention of rickets, malnutrition, anemia, infectious diseases, exacerbation of concomitant somatic pathology, preparation for surgery, counseling and, if necessary, treatment with related specialists, filling out the history of the child's development with examination data and conclusions of consultants, registration of stage and postoperative epicrisis, providing rehabilitation treatment in the postoperative period. Dental surgeon: surgical treatment in terms determined by the nature of the congenital defect, surgical correction of secondary defects and deformities, comparison and analysis of examination data by other specialists, direct and constant contact with parents, dynamic observation of children to analyze the results of treatment and consistently change the applied methods, correction and analysis of the results of complex treatment and accounting for effectiveness, development and improvement of forms and methods of sanitary and educational work, improvement of the clinical examination system, coordination of the work of all specialists involved in the treatment and rehabilitation of a child with CLAP.

Periods of active observation: neonatal period, first year of life, 1.5-4 years, 6-7 years, 912 years, systematic observation before being removed from dispensary registration. Orthodontist: ensuring full feeding of the child (obturators, separating plates, etc.), preand postoperative orthodontic treatment, prevention and treatment of secondary deformities of the dentition, restoration of the dentition.

Periods of active observation: newborns, before and after surgery, the period of mixed bite, systematic observation until the complete formation of a permanent bite.

Speech therapist: speech therapy before and after uranostaphyloplasty, training of the muscle frame of the soft palate, pharyngeal wall, development of speech breathing, preand postoperative speech therapy, development of phonemic hearing, formation of 
coherent speech.

Periods of active observation: 1-2 years, 4-5 years, 7-13 years.

Dentist: planned oral cavity sanitation (taking into account caries decompensation and at least 2 times a year), dental treatment in the preoperative period.

Periods of active observation: from the moment the milk teeth appear.

Otorhinolaryngologist: conservative or surgical treatment of diseases of the ENT organs, hearing control, ensuring the timely conduct of planned operations.

Periods of active observation: preschool period; periods preceding planned operations; as necessary prior to deregistration.

Exercise therapy doctor: development of an exercise therapy program corresponding to the child's condition, which should take into account the degree of lag in physical, motor and mental development, the presence of concomitant diseases, a combination of pathological organ lesions, systematic long-term exercise therapy using special massage techniques and exercises for the muscles of the maxillofacial area, improvement functions of the child's respiratory system, teaching parents the basics of a hygienic hardening regime, basic massage techniques and exercises individually selected for the child.

Active observation periods: 1-12 months; periods preceding planned operations; 4-5 years old; 7-13 years old; as necessary prior to deregistration.

Psychoneurologist: medical and pedagogical rehabilitation measures, corrective drug therapy, psychotherapy.

Periods of active observation: 4-6 years (the period of the formation of lucid speech), at all stages of the child's psychosocial development before being removed from the register.

Geneticist: establishing the diagnosis and the type of inherited transmission (if any), predicting the degree of risk of birth in a proband or his family members children with CLAP.

Periods of active observation: newborns, puberty, marriage.

Other specialists. According to indications, depending on the identified pathology.

Conclusions. 1. The main principles of successful treatment are an integrated approach, the implementation of all the main stages of surgical treatment at the age of up to 1 year, dispensary observation for 18 years in a specialized center, in this regard, there should be 
a clear step-by-step rehabilitation and well-functioning and coordinated work of doctors of various profiles under the guidance of specialists of the Department of Pediatric Oral and Maxillofacial Surgery.

2. Treatment of children with congenital clefts of the upper lip and palate should be carried out by teams of highly qualified specialists (maxillofacial surgeon, speech therapist, orthodontist, pediatrician, neurologist, ENT doctor, geneticist, psychologist) and in specialized centers.

3. Early speech therapy assistance is needed for the development of normal speech breathing and correct articulation, correction of violations of sound pronunciation, nasal (nasal) tone of voice, careful control over the general speech development of the child and timely elimination of the lag in the development of phrasal speech, vocabulary, preparation for training in general education school.

4. Today, as never before in the history of medicine, the high level of medical technology allows for the complete rehabilitation of a child at an early age. Modern methods of surgical, orthodontic treatment and speech therapy training make it possible to ensure that the baby has perfect facial contours, normal speech and, smiling, demonstrates a beautiful and continuous dentition.

\section{References}

1. Bergendal B., Ekman A., Nilsson P. Cleft lip and palate // Int. J. Oral Maxillofac. Implants, 2008. Vol. 23, № 3. P. 520-524.

2. Byrd H.S., Salomon J. Primary correction of the unilateral cleft nasal deformity // Plast. Reconstr. Surg. 2009. Vol. 106, № 6. P. 1276-1286. Cleft lip and palate / B. Bergendal et al. Capa Istanbul, 2010. 152 p.

3. Egan T., Antoine G. Cleft lip and palate // Facial plastic, reconstructive, and trauma surgery. N.Y.: Marcel Dekker, 2008. P. 359-378.

4. Epker B.N. Secondary surgery to correct CLP nasal deformity // 3 th Biennial World Congress International Cleft Lip and Palate Foundation. Halifax, 2004. P. 66.

5. Abolmasov N.G., Abolmasov N.N. Orthodontics: ucheb. posobie. M .: Medicine, 2008. 415 p.

6. Anoxina A.V. Rannee vыyavlenie i rehabilitation detey $s$ narusheniyami formirovaniya zubochelyustnoy sistemy: ucheb. posobie. Kazan: Medicine, 2004. 184 p. 
7. Anoxina A.V. Removal of harmful privychek and impaired zubochelyustnoy system in children: ucheb. posobie / Kazan. gos. med. acad. Kazan: Prayd, 2009. 52 p.

8. Balandina E.A. Factors of risk of birth of children with rasshchelinoy verxney guby i neba in Permskom krae // Logoped. 2010. № 4. S. 6-11.

9. Belchenko V.A. Cherepno-litsevaya surgery: rukovodstvo dlya vrachey. M .: MIA, 2006. 340 p.

10. Borovaya M.L. Prevention of tooth decay in children up to 10 years of age with VRGN sodium fluoride tablets // Modern dentistry. 2000. № 2. S. 44-46.

11. Gonchakov G.V., Prityko A.G., Gonchakova S.G. Xirurgicheskoe lechenie detey s vrojdennymi rasshchelinami verxney guby // Dentology: materials 7-go Vseros. nauch. foruma. M., 2005. S. 7-77.

12. Davletshin N.A. Sposob shchadyashchey uranostaphyloplastiki, preduprejdayushchiy ukorochenie i rubtsevanie myagkogo neba // Kazanskiy meditsinskiyurnal. 2008. № 4. S. 563-564.

13. Kamysheva L.I. Orthodontic treatment of children with rasshchelinami verxney guby, alveolyarnogo otrostka i neba $v$ usloviyax polikliniki $v$ period molochnyx zubov: ucheb. posobie / Mosk. gos. med.-stomatol. un-t. M., 2001. 40 p.

14. Computer modeling of rhinoplastic surgery / A.S. Kiselev, K.M. Krylov, I.V. Kraynik et al. // Rossiyskaya rhinology. 2002. № 2. S. 171-172.

15. Korsak A.K. Lyubetskiy A.V., Lapkovskiy V.I. Xirurgicheskoe lechenie detey s vrojdennymi rasshchelinami verxney guby i neba $v$ rannem vozraste // Sovremennaya stomatologiya.2007. № 4. C. 62-65.

16. Lavrikov V.G., Zernov A.B., Stenina C.B. Etapnost ustraneniya zubochelyustnyx deformatsiy $\vee$ kompleksnoy terapii vrojdennyx rasshchelin litsa // Dentology. 2004. $\wedge 2$. S. 44-45.

17. Lopuxova N.B. Klinicheskaya kartina i osobennosti ortopedicheskogo lecheniya vzroslyx patsientov s vrojdennoy rasshchelinoy guby i neba // Dentologiya. 2004. № 2. S. 51-53.

18. Orthodontics: ucheb. posobie dlya studentov stomatologicheskogo fakulteta, vrachey internov / V.I. Kutsevlyak, A.V. Samsonov, S.A. Sklyar et al .; under red. V.I. Kutsevlyaka. Kharkiv: XGMU, 2005. 464 p.

19. Osnovnye printsipy kompleksnogo podkhoda $v$ lechenii bolnyx $s$ vrojdennymi rasshchelinami / B.N. Davydov, V.G. Lavrikov, A.V. Zernov et al.// Dentistry of childhood and prophylaxis. 2009. № 3-4. S. 18-20.

20. Persin L.S., Elizarova V.M., Dyakova S.V. Dentistry of childhood. 4th ed. M .: Medicine, 2003. 640 p.

21. Persin L.S., Elizarova V.M., Dyakova S.V. Dentistry of childhood: textbook. 5th ed. M $\therefore$ Medicine, 2006. 640 p. 